\title{
Multifractal model of magnetic susceptibility distributions in some igneous rocks
}

\author{
M. E. Gettings \\ US Geological Survey, Tucson, Arizona, USA \\ Correspondence to: M. E. Gettings (mgetting@usgs.gov) \\ Received: 17 August 2012 - Revised: 1 November 2012 - Accepted: 12 November 2012 - Published: 23 November 2012
}

\begin{abstract}
Measurements of in-situ magnetic susceptibility were compiled from mainly Precambrian crystalline basement rocks beneath the Colorado Plateau and ranges in Arizona, Colorado, and New Mexico. The susceptibility meter used measures about $30 \mathrm{~cm}^{3}$ of rock and measures variations in the modal distribution of magnetic minerals that form a minor component volumetrically in these coarsely crystalline granitic to granodioritic rocks. Recent measurements include 50-150 measurements on each outcrop, and show that the distribution of magnetic susceptibilities is highly variable, multimodal and strongly non-Gaussian. Although the distribution of magnetic susceptibility is well known to be multifractal, the small number of data points at an outcrop precludes calculation of the multifractal spectrum by conventional methods. Instead, a brute force approach was adopted using multiplicative cascade models to fit the outcrop scale variability of magnetic minerals. Model segment proportion and length parameters resulted in 26676 models to span parameter space. Distributions at each outcrop were normalized to unity magnetic susceptibility and added to compare all data for a rock body accounting for variations in petrology and alteration. Once the best-fitting model was found, the equation relating the segment proportion and length parameters was solved numerically to yield the multifractal spectrum estimate. For the best fits, the relative density (the proportion divided by the segment length) of one segment tends to be dominant and the other two densities are smaller and nearly equal. No other consistent relationships between the best fit parameters were identified. The multifractal spectrum estimates appear to distinguish between metamorphic gneiss sites and sites on plutons, even if the plutons have been metamorphosed. In particular, rocks that have undergone multiple tectonic events tend to have a larger range of scaling exponents.
\end{abstract}

\section{Introduction}

Measurements of magnetic susceptibility of rocks have recently experienced renewed interest. At regional and crustal scales, Maus and Dimri (1994) and Pilkington and Todoeschuck (1995) have shown that distributions of magnetic susceptibilities can be modeled with fractals. Further work by Lovejoy et al. (2001) and Pecknold et al. (2001) demonstrated that at these scales the distributions are multifractal. At sub-regional scales, drill hole logs of magnetic susceptibility were well modeled with fractals by Pilkington and Todoeschuck (1993) and were shown to be multifractal in general by Gettings (1995), Fedi (2003), Gettings (2005) and Bansal et al. (2010).

Measurements of magnetic susceptibility at the scale of a few meters (outcrop scale) have been observed to be multimodal (Clark and Emerson, 1991; Oniku et al., 2008; Gettings, 2011a, 2012) and multifractal (Gettings, 2011a,b, 2012). This report describes the development and application of a multifractal model of magnetic susceptibility distribution at outcrop scale for a number of representative sites in the southwest United States.

Traditionally, measurements of magnetic susceptibility on an outcrop have consisted of a single or a few observations (for example, Gettings et al., 1994; Altstatt et al., 2002; Sanger and Glen, 2003; Saltus and Haeussler, 2004) and publishing the number of observations, the mean, and the standard deviation. At the outcrop scale, susceptibility measurements with modern high-resolution instruments often yield standard deviations larger than the observed mean susceptibility. Studies of the distribution of magnetic susceptibilities at various scales are rare; Lindsley et al. (1966) give a table that gives the likelihood of susceptibility being less than given values. Clark and Emerson (1991) and Clark (1997) 
described the large variability even at outcrop scale and described bimodal susceptibility distributions for granite due to there being two distinct petrologic granite types. Gettings et al. (1994) showed that standard deviation plotted versus the mean value of magnetic susceptibility often clusters enabling discrimination of rock type or formation in some cases. Altstatt et al. (2002) and Sanger and Glen (2003) have recognized the large standard deviations and increased the number of measurements at an outcrop to approximately 20 or more.

Modern portable magnetic susceptibility meters designed for use in the field tend to measure fairly small volumes of rock (about $30 \mathrm{~cm}^{3}$ for the instrument used in this study) and thus in coarsely crystalline rocks sense a variable volume of magnetic minerals since they are usually accessory minerals. Gettings (2012) has described the field procedures and multimodal distributions of magnetic susceptibility for seven sites in the American Southwest and related the variability to the variation of minor and accessory minerals in the lithologies studied, primarily igneous and metamorphic rocks of granodioritic to granitic composition. However, that report did not model the observed distributions; the model results are presented in this report. Peternell and Kruhl (2009), for example, give results that show the spatial distributions of minor (and accessory) minerals are multifractal in their distribution in the rock.

The problem of characterizing the distribution multifractal spectrum is complicated by the small number of observations, commonly 50 to 300 for sites in this study. For commonly used spectrum calculation techniques, thousands or tens of thousands of observations are normally used to enable reliable fits determining the spectrum. For this work, such a large number of measurements was impractical, and so another approach had to be adopted.

The observed data at outcrop scale resemble a onedimensional multiplicative cascade (Lovejoy and Schertzer, 1995; Schertzer and Lovejoy, 2004; Feder, 1988 "curdling with several length scales”). For example, Fig. 1 shows data from a site and a smoothed cascade with distribution that fits the data (discussed below) quite well. Note that peak location on the figure is arbitrary depending on where the measurements begin on the outcrop. Only the amplitudes and shapes of the peaks are compared. It was therefore decided to attempt to model the data from various rock bodies by brute force comparison with a suite of multiplicative cascades. For cascades that fit the data, the multifractal spectrum can be determined by numerical solution of the equation relating the sequence of mass exponents to the moment order (Feder, 1988). The remainder of this report will describe the model in detail, the data processing procedures used to group magnetic susceptibility measurements from several outcrops in the same rock body into one distribution for comparison to the models, and the results of the modeling for 12 rock bodies representative of the basement rock types in the southwest US.

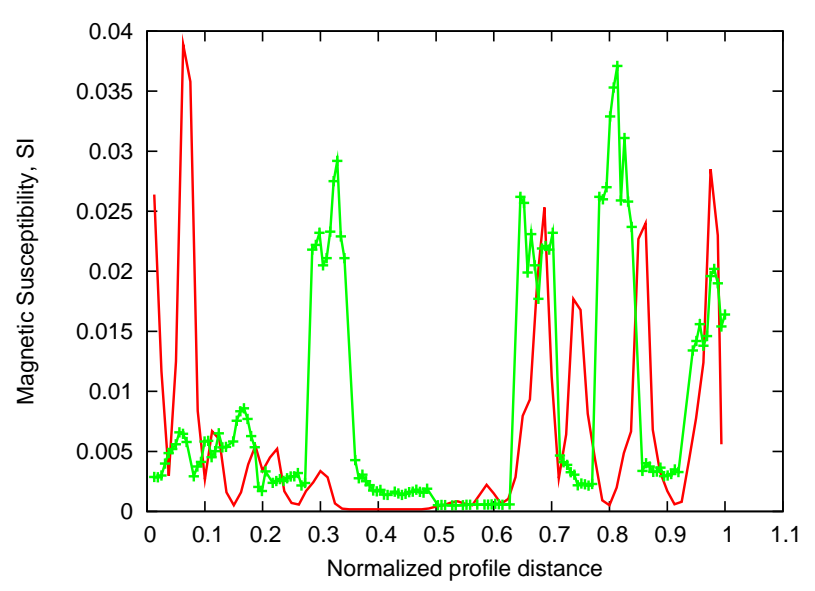

Fig. 1. Illustrative plot of observed magnetic susceptibilities (symbols) at an outcrop and the best fitting multiplicative cascade model. Note that only the amplitude and peak shapes are relevant; the location of the peaks along the distance axis is arbitrary.

\section{The model}

The model adopted was a multiplicative cascade with the following parameters: the number of segments at each generation of the cascade, the relative lengths of the segments, and the relative proportions of "mass" going into each segment at each subdivision of a segment (Feder, 1988). Both the segment lengths and the proportions sum to unity so that the process conserves "mass" for the total of the segments throughout the generation process. A line of unit length is subdivided by the number of segments into segments with length and "mass" determined by the parameter set of lengths and "mass" proportions. In the next generation, each segment is subdivided again using the set of lengths and proportions. At each generation, segment length is a product of the lengths through that generation, and the "mass" is a product of the proportions through that generation. For this work, three segments were used because the distributions from three segments visually appeared more similar to the observed data in fewer generations than using two segments. The sets of (three) segment lengths and proportions were randomly permuted at the subdivision of each segment. However the proportions and the lengths were permuted in the same way; that is, both the segment lengths and proportions were permuted together. Thus the completed multiplicative cascade models the amount of magnetic minerals within the susceptibility meter's sensing volume for a small distance perpendicular to the path of the instrument. The cascade is then smoothed using a weighted sum ("mass" of segments times their length) over a window on the cascade that models the sensing volume of the susceptibility meter. Although strictly speaking, the model volume is a half cylinder and whereas the meter's sensing volume is a hemisphere; given the uncertainties in the model, this is not believed to be significant. Moreover, 
the volume difference was accounted for in an approximate way by using a window movement increment on the cascade scaled in such a way that the hemisphere volume was approximated.

The scaling of the model was determined as follows. Calculation of the cascade using 3 segments to 7 generations yields $3^{7}=2187$ segments which in a one meter length would correspond to a segment length ("point") of approximately $0.5 \mathrm{~mm}$ if all segments were of equal length. Noting that the cascade process gives many segments of smaller length, this is a reasonable maximum size estimate for the accessory minerals in the rocks studied. Then using a 101-point window (0.01 of a unit line) gives a 5-cm-long half cylinder, which is comparable to the footprint of the susceptibility meter. The window was moved 20 points $(1 \mathrm{~cm})$ between each weighted sum to model the susceptibility meter's observations. The process yields about 500 model values. A histogram of the model values was then computed for the cascade model to compare with the histogram of the observed data.

In order to characterize a single geologic body that had magnetic susceptibility measurements at two or more outcrops within it, the assumption was made that the susceptibility distribution shape at each outcrop was essentially the same. Thus the histogram of measurements at each outcrop was normalized to unit magnetic susceptibility using a constant bin size and the resulting frequencies added and divided by the number of outcrops. This resulted in a normalized histogram of frequencies representing the samples of the geologic body. This procedure roughly corrects for differential alteration and petrologic variation between outcrops in the same rock body and enables the estimation of the multifractal spectrum for a geologic body rather than an outcrop of the body.

The multiplicative cascade process used results in segments of varying length. To simulate the susceptibility measurement, a weighted sum over a window of constant width similar to the coil diameter of the susceptibility meter needs to be calculated. If the cascade is represented by a set of $x_{i}$ and $y_{i}$ so that the segment length is $x_{i}-x_{i-1}$ and the "mass" is $y_{i}$, then the weighted sum in a window defined by $w_{2}-w_{1}$ is

$y_{\mathrm{W}}=\left[\sum_{x_{i-1} \geq w_{1}}^{x_{i} \leq w_{2}}\left(x_{i}-x_{i-1}\right) y_{i}\right] /\left(w_{2}-w_{1}\right)$.

The window is then moved by the desired increment and the sum calculation repeated. Many cases of the relation between the window edges and segment edges are possible depending upon relative lengths of segments and window widths so that writing a program to calculate the $y_{\mathrm{w}}$ needs some care.

For this study, an increment in segment lengths of 0.025 was chosen and the proportion increment used was 0.10 . Considering that the sum of the segment lengths and the pro- portions is each unity, 26676 model cascades are needed to span the parameter space with no duplicates. Only one realization of the 26676 cascades was computed. These were computed using a FORTRAN program in about 20 min on a multi-processor personal computer running the Linux operating system. The simulation of the susceptibility measures used a window width of 0.01 and window movement increment of 0.002 in a normalized profile length of unity. Computation of the windowing (Eq. 1) using a FORTRAN program for all the cascades took about $8 \mathrm{~min}$. This results in about 500 simulated measurements per cascade.

Next, histograms of the simulations were computed using a Perl histogram script (Krogh and Munch, 2005) called from an AWK program script (Aho et al., 1988) written to call the histogram script for a list of files. The number of bins in the histogram was 201 using a bin size of 0.005 . About 21 min were required to complete the histograms for 26676 the model simulations.

The model simulations were then compared to the data histograms (with the same bin size and range) using a FORTRAN program. Best fits were determined by those that had the minimum $\chi^{2}$ (Bevington, 1969) and minimum mean absolute deviation. Once the best fit was determined, the sequence of mass exponents $\tau(q)$ as a function of the moment order $q$ was determined (Feder, 1988) by numerical solution of

$\sum_{i=1}^{3} p_{i}^{q} l_{i}^{\tau(q)}=1$

where $p_{i}$ and $l_{i}$ are the proportion and segment length parameters, respectively. The multifractal spectrum $\alpha, f(\alpha)$ was then obtained from (Feder, 1988)

$\alpha(q)=-\frac{d \tau(q)}{d q}$

and

$f(\alpha(q))=q \alpha(q)+\tau(q)$.

\section{Fits to data}

Twelve rock bodies for which magnetic susceptibility data had been collected were modeled with the multifractal model. These bodies include Precambrian igneous and metamorphic basement rocks of the Colorado Plateau and southern Basin and Range, and Late Cretaceous to Tertiary age intrusive quartz monzonites, granodiorites and granites in the southern Arizona Basin and Range. For each rock body, the frequency distribution of the observed susceptibilities was normalized and combined with other sites within the same body to obtain a distribution assumed to represent that rock body. The resulting distribution was then compared with the catalog of models described in the last section and the best 


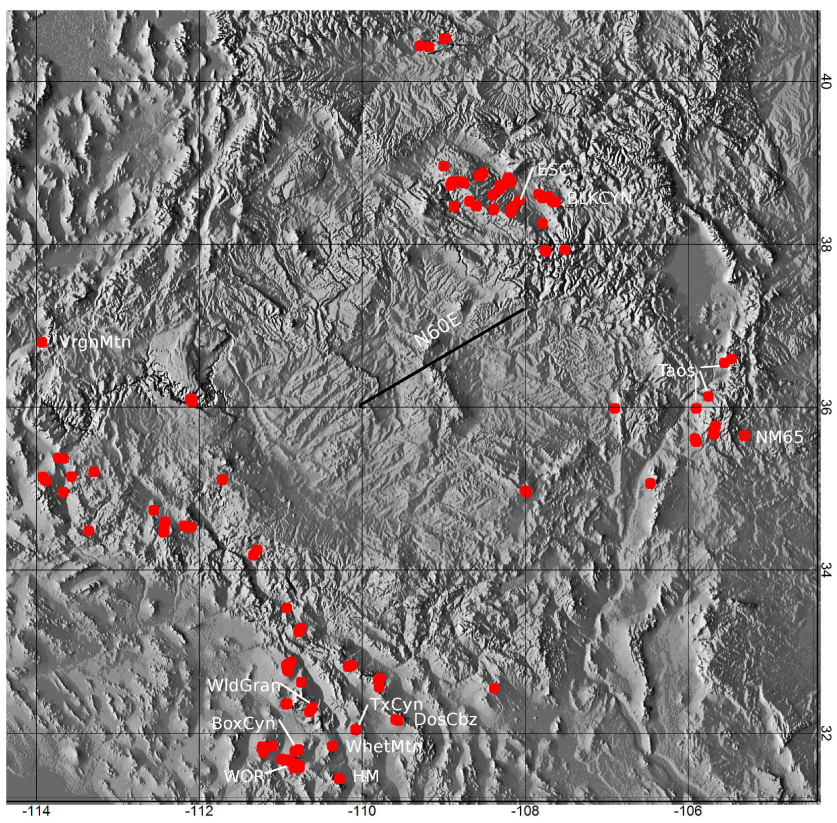

Fig. 2. Locations in the American Southwest where magnetic susceptibility measurements have been made. Labeled areas are the rock bodies discussed in this report. Horizontal axis is degrees of west longitude, and vertical axis is degrees of north latitude. Heavy black line in central part of the image shows the $\mathrm{N} 60^{\circ} \mathrm{E}$ tectonic extension direction discussed in the text.

fitting model selected. A summary of the best fitting model parameters is given in Table 1, and the site locations are shown in Fig. 2. For brevity, only one rock body magnetic susceptibility distribution will be shown here - the Precambrian diorite of the Huachuca Mountains (HM in Table 1). This site is representative of the model results, falling about mid-range in terms of the quality of fit.

The histograms of Fig. 3 for the HM body demonstrate that it is surprisingly difficult to fit the observed distributions. The overall fit is reasonably good with model values at or near all peaks in the distribution. The main misfit is in amplitude for most of the model fit. Some model fits were not as good as Fig. 3, whereas others were better, as evidenced in the fitting parameters $\chi^{2}$ and mean absolute deviation shown in Table 1 .

Considerable effort was expended in a search for relationships between the segment lengths and proportion values for the best-fitting models, but only one consistent relationship has been identified. Among the best fitting models, there are generally one long and two shorter segments in the generator and a single large proportion relative to the other two. However, there is no consistent relation between the long segment and the large proportion. Recalling that the segment lengths and proportions are permuted together in this model, if one considers the relative density, that is, the proportion divided by the segment length, one segment tends to have a dominant density and the other two a smaller nearly equal density. This

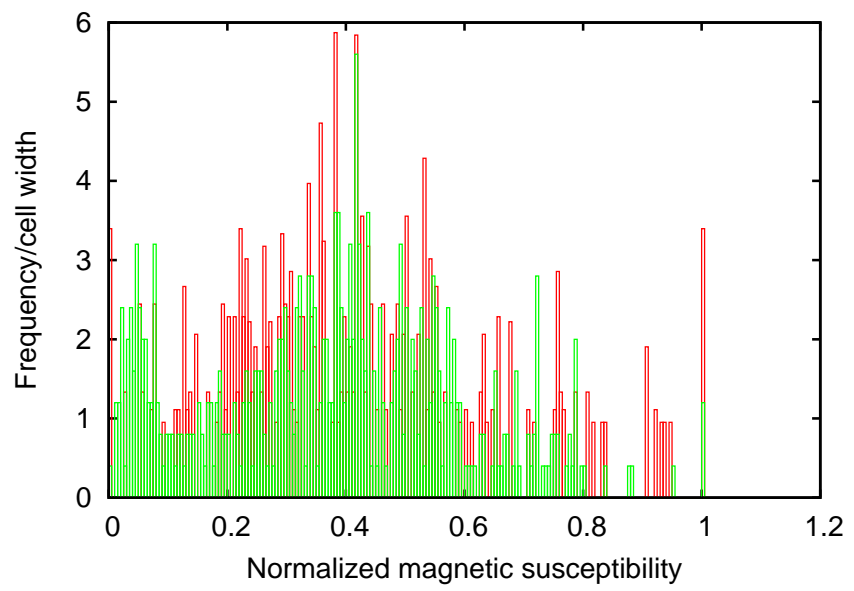

Fig. 3. Histogram of normalized magnetic susceptibility (red) from the three sites in the Huachuca Mountains and the best fitting multiplicative cascade model (green).

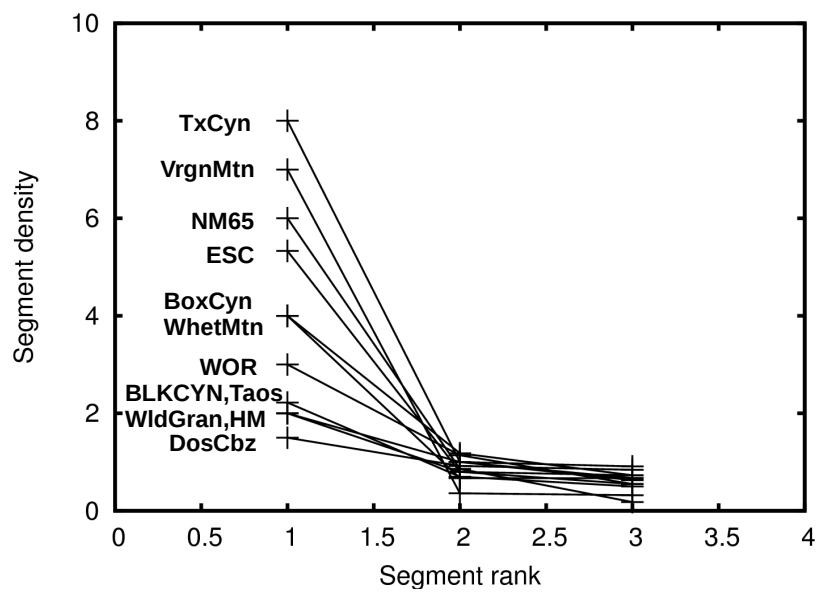

Fig. 4. Ranked relative densities (segment proportion divided by segment length) for the best fitting models of the 12 rock bodies.

is shown in Fig. 4 for the 12 rock bodies. Although there is a possibility this is a numerical effect, the use of random permutations of the segment length-proportion set should offset any systematic numerical effect. Also, the catalog of parameter variation for segment length and proportion is complete, that is large proportions with small segment lengths and viceversa, so that there should not be a bias in the combination of the two parameters. Histograms of the distribution of the segment lengths and segment proportions for both the 12 best fits, and for the five best fits from the 12 localities did not reveal any useful relationships, nor did plots of segment length versus segment proportion. 
Table 1. Parameters of the best fits to the 12 rock bodies discussed in this report. $\chi^{2}$ is the reduced chi-square of the fit; MAD is the mean absolute deviation of the fit; $l_{1}, l_{2}, a n d l_{3}$ are the segment length parameters; $p_{1}, p_{2}$, and $p_{3}$ are the relative proportion parameters; $\alpha_{\min }, \alpha_{\text {sprt }}$, and $\alpha_{\max }$ are the Lipschitz-Hölder exponent minimum, support dimension (1.00), and maximum values.

\begin{tabular}{llrrrrrrrrrrr}
\hline Site & Rock type & $\chi^{2}$ & $\mathrm{MAD}$ & $l_{1}$ & $l_{2}$ & $l_{3}$ & $p_{1}$ & $p_{2}$ & $p_{3}$ & $\alpha_{\min }$ & $\alpha_{\text {sprt }}$ & $\alpha_{\max }$ \\
\hline BLKCYN & Pc gneiss+granodiorite & 1.29 & 0.776 & 0.200 & 0.200 & 0.600 & 0.4 & 0.2 & 0.4 & 0.571 & 1.113 & 1.794 \\
ESC & Pc granodiorite & 1.88 & 0.851 & 0.075 & 0.375 & 0.550 & 0.4 & 0.3 & 0.3 & 0.354 & 1.310 & 2.013 \\
NM65 & Pc granitic gneiss & 2.86 & 0.890 & 0.550 & 0.350 & 0.100 & 0.1 & 0.3 & 0.6 & 0.222 & 1.918 & 3.852 \\
Taos & Pc gneiss and amphibolite & 2.46 & 1.030 & 0.200 & 0.575 & 0.225 & 0.1 & 0.4 & 0.5 & 0.466 & 1.168 & 1.638 \\
BoxCyn & Pc granodiorite & 2.05 & 0.957 & 0.425 & 0.025 & 0.550 & 0.5 & 0.1 & 0.4 & 0.636 & 1.089 & 1.523 \\
DosCbz & Pc granodiorite & 1.86 & 0.852 & 0.475 & 0.325 & 0.200 & 0.4 & 0.3 & 0.3 & 0.762 & 1.025 & 1.198 \\
HM & Pc diorite & 1.42 & 0.867 & 0.400 & 0.050 & 0.550 & 0.4 & 0.1 & 0.5 & 0.789 & 1.020 & 1.119 \\
WOR & Tertiary granodiorite & 1.93 & 0.925 & 0.550 & 0.350 & 0.100 & 0.3 & 0.4 & 0.3 & 0.528 & 1.195 & 2.014 \\
WldGran & Tertiary two-mica granite & 0.85 & 0.672 & 0.250 & 0.550 & 0.200 & 0.2 & 0.4 & 0.4 & 0.571 & 1.092 & 1.526 \\
VrgnMtn & Pc gneiss+amphibolite & 2.88 & 0.872 & 0.625 & 0.275 & 0.100 & 0.2 & 0.1 & 0.7 & 0.155 & 1.864 & 3.424 \\
WhetMtn & Pc chloritized granite & 5.84 & 1.434 & 0.300 & 0.600 & 0.100 & 0.2 & 0.4 & 0.4 & 0.398 & 1.241 & 1.788 \\
TxCyn & Tertiary granite & 3.67 & 0.974 & 0.500 & 0.025 & 0.475 & 0.5 & 0.2 & 0.3 & 0.439 & 1.192 & 1.608 \\
\hline
\end{tabular}

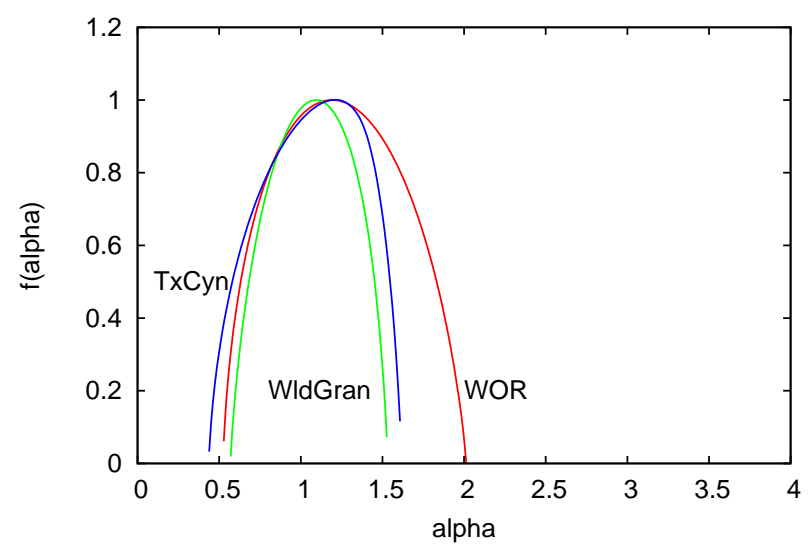

Fig. 5. Best-fitting model multifractal spectrum $f(\alpha)$ vs. $\alpha$ for rock bodies of Tertiary granite and granodiorite bodies in southern Arizona. WOR (red line; Whipple Observatory Road) is on the west flank of Mt. Hopkins; TxCyn (blue line) is the Texas Canyon granite in the northern Dragoon Mountains; and WldGran (green line) is the Wilderness Granite of the Santa Catalina Mountains.

\section{Discussion}

The multifractal spectrum was estimated by solving equations 2 through 4 numerically using the the segment length and proportions from the best-fitting models based on the fitting parameters $\chi^{2}$ and mean absolute deviation (Table 1). These 12 spectra are shown in Figs. 5 through 7. Figure 5 shows the multifractal spectra for the three Tertiaryage granite and granodiorite bodies. The two granites (Keith et al., 1980; Cooper and Silver, 1964) TxCyn and WldGran have similar spectra, whereas that for the granodiorite WOR (Drewes, 1976) spans a larger range of $\alpha$.

Figure 6 shows the results for the Precambrian diorite, granodiorite and granite bodies studied in southern Arizona. Lo-

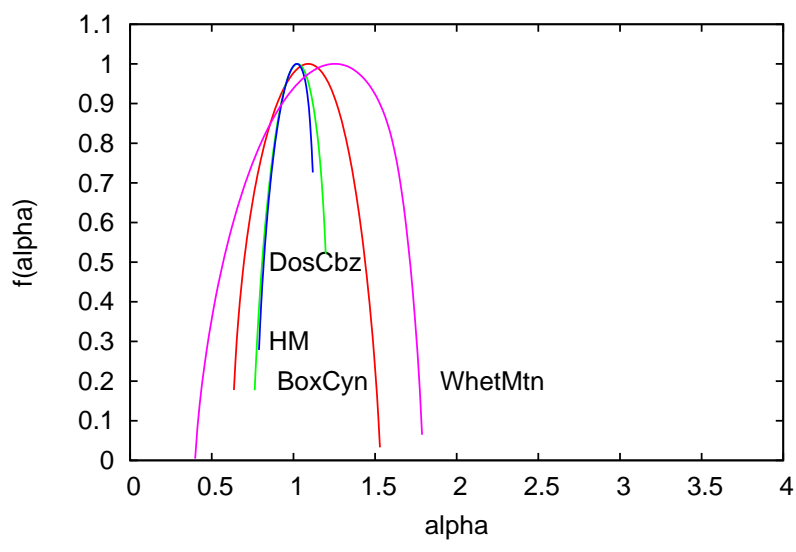

Fig. 6. Best-fitting model multifractal spectrum $f(\alpha)$ vs. $\alpha$ for rock bodies of Precambrian age in southern Arizona. WhetMtn (magenta line) is in the northern Whetstone Mountains; BoxCyn (red line) is in the northeastern Santa Rita Mountains; HM (blue line) is in the central eastern Huachuca Mountains; and DosCbz (green line) is on the south central flank of the Dos Cabezas Mountains.

cality WhetMtn has the largest range of exponents $\alpha$ and is the only true granite (Wrucke and Armstrong, 1984), but it is also somewhat chloritized at both outcrops that were accessible. HM, Huachuca Mountains diorite (Hayes and Raup, 1968), has the narrowest range of exponents $\alpha$ and is the most mafic of the rock bodies studied. Of the two granodiorites, DosCbz (Drewes et al., 1988)) and BoxCyn (Drewes, 1976), DosCbz is the more mafic in hand specimen and has magnetite contents of about 0.5 to 1.0 percent (Drewes et al., 1988). Both are very coarse-grained, with orthoclase (microperthite) crystals up to $7 \mathrm{~cm}$.

Figure 7 shows the resulting multifractal spectra for the remaining localities in Colorado, New Mexico, and the Virgin Mountains in northwestern Arizona. Both localities NM65 


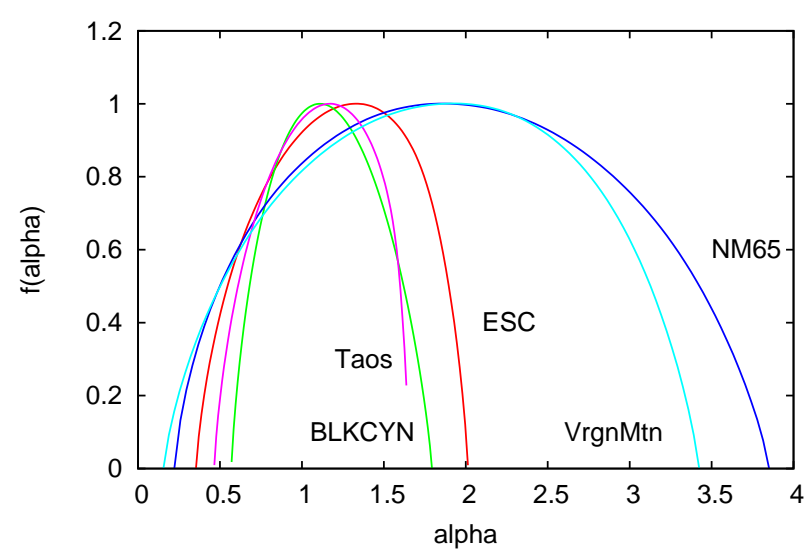

Fig. 7. Best-fitting model multifractal spectrum $f(\alpha)$ vs. $\alpha$ for rock bodies of Precambrian age in southwest Colorado, western New Mexico, and northwest Arizona. ESC (red line) is in Escalante Canyon in the northeast central portion of the Uncompahgre uplift; BLKCYN (green line) is the Black Canyon of the Gunnison River, southwest Colorado; Taos (magenta line) includes four sites northnortheast of Taos, New Mexico; NM65 (blue line) is west of Las Vegas, New Mexico, and VrgnMtn (turquoise line) is in the Virgin Mountains northeast of Mesquite, Nevada.

and VrgnMtn are composed of steeply dipping and deformed foliated granitic gneiss with interlayered amphibolitic schist (Baltz, 1972; Moore, 1972). These two localities appear to be distinctly different from all the others, having a very large range of scaling exponents $\alpha$. Locality BLKCYN includes seven sites of both metasedimentary gneisses and schists (four sites) as well as the coarse-grained Vernal granodiorite (three sites) (Hansen (1971) and Hansen (1987)), but no significant difference was observed in the normalized magnetic susceptibility distributions between the metamorphic rocks and the granodiorite. The difference in spectrum between the metamorphic rocks of the Black Canyon of the Gunnison and the New Mexico and Virgin Mountains sites may be due to the sedimentary origin of the Black Canyon rocks. The BLKCYN spectrum is very similar to the Precambrian BoxCyn granodiorite. These rocks are similar in their petrography also (Hansen, 1987; Drewes, 1976). The Taos area rocks come from four sites, metamorphic gneiss and amphibolite of Santa Catalina Lake area, a granite body somewhat weathered, and metamorphic amphibolitic gneisses (2 sites). These sites with the exception of the granite have protoliths that are somewhat more mafic (Reed et al., 1983) than other metamorphic localities in the study. The Precambrian granodiorite of Escalante Canyon, Colorado (Williams, 1964), has a spectrum very similar to that of the Tertiary granodiorite WOR in the Santa Rita Mountains of Arizona.

Among the southern Arizona localities, there is a geographic relationship among sites with similar multifractal spectra. The direction of regional extension forming the late Tertiary southern Basin and Range is $\mathrm{N} 60^{\circ} \mathrm{E} \pm 20^{\circ}$ (Rehrig and Reynolds, 1980), and the localities with similar spectra line up approximately along this axis. DosCbz and HM are the most southeast of the sites, lie along a line in the extension direction, and have quite similar spectra. WhetMtn, WOR, and TxCyn are somewhat similar in their spectra and lie along the extension axis parallel but northwest of the line connecting DosCbz and HM. Finally, the most northwest of the sites, WldGran and BoxCyn have similar spectra, although they are closer to north-south of each other. Whether this distribution has any tectonic meaning is unknown, but it is known that the extension direction does control Tertiary magmatism associated with the formation of the southern Basin and Range and the uplift of core complexes at least in some cases (Rehrig and Reynolds, 1980; Keith et al., 1980).

Localities VrgnMtn and NM65 occur in the marginal zone on the west and east sides of the Colorado Plateau and are composed of similar lithologies, and so might be expected to have similar spectra if the lithology and tectonic history exert any influence over the multifractal spectra. The same holds true for the Taos and BLKCYN sites; they are both in a similar tectonic relationship on a faulted and uplifted zone throughout the northeast part of the Colorado Plateau. Locality ESC is similar in that it is at the core of the Uncompahgre uplift, but it is probably older than the uplift and volcanism associated with the Taos and BLKCYN areas (Williams, 1964; Reed et al., 1983; Hansen, 1987). The fact that separate localities with similar lithologies and tectonic histories have similar multifractal spectra suggests that the spectral estimates are at least approximately correct since rocks with similar mineralogy and evolution would be expected to have similar spectra.

\section{Conclusions}

This report outlines the results of a test of brute-force estimation of the multifractal spectrum by fitting an observed distribution to a catalog of multiplicative cascade models. The author believes this approach was moderately successful but not perfect. Future research should consider some other approaches, for example the multifractional Brownian motion model (for example, Peltier and LevyVehel, 1995; Coeurjolly, 2005). However, the small dataset problem remains and such an approach would probably still require the generation of a model catalog by methods such as those described by, for example, Chan and Wood (1998), Chan (1999), or Reidi (2003).

This work has combined the data observations from several outcrops in a single geologic body to approximate the magnetic susceptibility distribution for the body. This was done by normalizing to unit magnetic susceptibility the data for each outcrop so that they could be combined. In a crude way this accounts for petrologic and alteration variations within the geologic body, but, by considering only the shape of the data distribution, any information contained in the 
measured intensities of susceptibility is lost. Assuming that this method is representative and that the multifractal spectra found from the best fits to the data distributions are reasonable estimates of the true spectra, the spectra appear to contain information regarding the tectonic history of the rock bodies studied. In particular, the more mafic compositions have a narrower range of scaling exponents in their multifractal magnetic susceptibility spectrum. Rock bodies with more complex tectonic histories including one or more metamorphic or alteration episodes have a broader range of scaling exponents, perhaps corresponding to new minerals within the rock along with the remnant minerals of the protolith. The spectra of sites in similar tectonic environments like the Colorado Plateau are similar, including environments on the margins of the plateau, those in subsequent magmatic and uplift events, and in bodies of similar composition and tectonic history.

In the case of the southern Arizona sites, an additional factor may be present from the mid-Tertiary extensional event forming the southern Basin and Range and uplifting and exposing the metamorphic core complexes. Spectra from these sites exhibit similarities for bodies approximately geographically aligned along the axis of the extension direction of northeast-southwest. Spectra for other bodies in alignment with the extension but displaced northwest or southeast are different, so that there appear to be northeast-trending "corridors" of similar spectra. These corridors correlate with northeast-trending structural zones that accommodate the extension differently in different zones. This accounts for the offsets and bends in the northwest-trending ranges and basins.

The fact that relations observed in the estimated spectra are consistent with the petrologic and tectonic relations at and between the various sites suggests that these spectra are indeed reasonable estimates of the true data spectra. Future work should be undertaken to further test this approach and its validity in the case of datasets known to be multifractal but for which the acquisition of thousands to hundreds of thousands of data points in order to use conventional methods is impractical. Further research should also be undertaken to refine and explore the relationship between the range of magnetic susceptibility multifractal scaling exponents and the tectonic history and mineral stability of the rocks in localities where the petrology and tectonic event dates are well known.

Acknowledgements. The author acknowledges the assistance of several colleagues in the course of this work, Discussions with Mark Bultman have been helpful. F. S. Fisher supported the beginning of this work starting several decades ago. The work was completed as parts of projects of the US Geological Survey. Louis de Montera, Mark Bultman, and Victor Mossotti provided valuable reviews that improved the manuscript.
Edited by: J. Wanliss

Reviewed by: L. de Montera and one anonymous referee

\section{References}

Aho, A. V., Kernighan, B. W., and Weinberger, P. J.: The AWK programming language, Addison-Wesley Longman Publishing Co., Inc., Boston, MA, USA, 1988.

Altstatt, A., Saltus, R., Bruhn, R., and Haeussler, P.: Magnetic susceptibilities measured on rocks of the upper Cook Inlet, Alaska, US Geological Survey Open-File Report 02-0139, 1, 1-18, 2002.

Baltz, E.: Geologic map and cross sections of the Gallinas Creek area, Sangre De Cristo Mountains, San Miguel County, New Mexico, US Geological Survey Miscellaneous Geologic Investigations Map I-673, 1 Map, scale 1:24 000, 1972.

Bansal, A., Gabriel, G., and Dimri, V.: Power law distribution of susceptibility and density and its relation to seismic properties: An example from the German Continental Deep Drilling Program (KTB), J. Appl. Geophys., 72, 123-128, doi:10.1016/j.jappgeo.2010.08.001, 2010.

Bevington, P.: Data Reduction and Error Analysis for the Physical Sciences, McGraw-Hill Book Company, 1969.

Chan, G.: An effective method for simulating Gaussian random fields, in: Proceedings of the statistical Computing section, available at: www.stat.uiowa.edu/ grchan/, Amerir. Statist., 133-138, 1999.

Chan, G. and Wood, A.: Simulation of Multifractional Brownian Motion, in: Proceedings in Computational Statistics 1998, edited by: Payne, R. and Gree, P., 233-238, 1998.

Clark, D.: Magnetic petrophysics and magnetic petrology : aids to geological interpretation of magnetic surveys, AGSO J. Austr. Geol. Geophys., 17, 83-103, 1997.

Clark, D. and Emerson, D.: Notes on rock magnetization characteristics in applied geophysical studies, Exploration Geophys., 22, 547-555, 1991.

Coeurjolly, J.-F. C.: Identification of multifractional Brownian motion, Bernoulli, 11, 987-1008, doi:10.3150/bj/1137421637, 2005.

Cooper, J. and Silver, L.: Geology and ore deposits of the Dragoon quadrangle, Cochise County, Arizona, USGS PP 416., US Geological Survey Professional Paper 416, 196 pp., 13 pl., 1964.

Drewes, H.: Plutonic rocks of the Santa Rita Mountains, southeast of Tucson, Arizona, US Geological Survey Professional Paper 915, 75 pp., 1976.

Drewes, H., Klein, D. P., and Birmingham, S. D.: Volcanic and Structural Controls of Mineralization in the Dos Cabezas Mountains of Southeastern Arizona, US Geological Survey Bulletin 1676, 1988, 45, 1 plate, 1988.

Feder, J.: Fractals, ISBN 0-306-42851-2, Plenum Press, New York, 1988.

Fedi, M.: Global and Local Multiscale Analysis of Magnetic Susceptibility Data, Pure Appl. Geophys., 160, 2399-2417, doi:10.1007/s00024-003-2401-5, 2003.

Gettings, M.: Cantor set models of magnetic sources, Abstracts Week B, XXI General Assembly of the International Union of Geodesy and Geophysics, Boulder, Colorado, B, p. B193, 1995.

Gettings, M. E.: Multifractal magnetic susceptibility distribution models of hydrothermally altered rocks in the Needle Creek Igneous Center of the Absaroka Mountains, Wyoming, 
Nonlin. Processes Geophys., 12, 587-601, doi:10.5194/npg-12587-2005, 2005.

Gettings, M.: Non-Gaussian Distribution of In-Situ Magnetic Susceptibilities in Basement Rocks, Southwest United States, in: XXV IUGG General Assembly: Earth on the Edge: Science for a Sustainable Planet Abstracts, Melbourne, Australia, 28 June-7 July 2011, 2523, 2011a.

Gettings, M. E.: Multifractal Models of the Distribution of Magnetic Susceptibilities in Coarsely Crystalline Rocks, Abstract NG34A-02, in: 2011 Fall Meeting Abstracts, American Geophysical Union, San Francisco, Calif., 5-9 Dec., NG34A-02, $2011 b$.

Gettings, M.: In-situ distributions of magnetic susceptibility in some igneous rocks, Geophysics, submitted, 2012.

Gettings, M. E., Fisher, F. S., Gettings, P. E., and Luedke, R. G.: Some magnetic properties of rocks from the Silverton Caldera area, western San Juan Mountains, Colorado, US Geological Survey Open-File Report 94-291, 94-291, 1-37, 1994.

Hansen, W. R.: Geologic Map of the Black Canyon of the Gunnison River and Vicinity, Western Colorado, Miscellaneous Geologic Investigations Map, 1971.

Hansen, W. R.: The Black Canyon of the Gunnison in Depth, Southwest Parks and Monuments Association, originally US Geological Survey Bulletin 1191, 2nd revised Edn., 1987.

Hayes, P. T. and Raup, R. B.: Geologic map of the Huachuca and Mustang Mountains, southeastern Arizona, US Geological Survey Miscellaneous Geologic Investigations Map I-509, 1 Map, scale 1:48000, 1968.

Keith, S. B., Reynolds, S. J., Damon, P. E., Shafiqullah, M., Livingston, D. E., and Pushkar, P. D.: Cordilleran Metamorphic Core Complexes, chap. Evidence for multiple intrusion and deformation within the Santa Catalina-Rincon-Tortolita crystalline complex, southeastern Arizona, Memoir 153, Geol. Soc. Am., 217 268, 1980.

Krogh, A. and Munch, K.: Histogram.pl, a perl script to make histograms, internet, available at: http://ib.berkeley.edu/labs/slatkin/ munch/scriptlist/histogram.txt, (last access: 21 November 2012), 2005.

Lindsley, D., Andreasen, G., and Balsley, J.: Handbook of Physical Constants, Memoir 97, chap. 25, Magnetic Properties of Rocks and Minerals, Geol. Soc. Am., 543-552, 1966.

Lovejoy, S. and Schertzer, D.: New Uncertainty Concepts in Hydrology and Water Resources, chap. 2. Multifractals and rain, Cambridge University Press, 61-103, doi:10.1017/CBO9780511564482, 1995.

Lovejoy, S., Pecknold, S., and Schertzer, D.: Stratified multifractal magnetization and surface geomagnetic fields, I. Spectral analysis and modelling, Geophys. J. Int., 145, 112-126, doi:10.1111/j.1365-246X.2001.00344.x, 2001.

Maus, S. and Dimri, V. P.: Scaling properties of potential fields due to scaling sources, Geophys. Res. Lett., 21, 891-894, doi:10.1029/94GL00771, 1994.

Moore, R.: Geology of the Virgin and Beaverdam Mountains, Arizona, Arizona Bureau of Mines Bulletin, 186, 65 pp. (incl. geologic map, scale 1:62 500), 1972.
Oniku, S. A., Osazuwa, I. B., and Meludu, O. C.: Preliminary report on magnetic susceptibility measurements on rocks within the Zaria granite batholith, Nigeria, 25, 203-213, Geofizika, 25, 203-213, 2008.

Pecknold, S., Lovejoy, S., and Schertzer, D.: Stratified multifractal magnetization and surface geomagnetic fields, II. Multifractal analysis and simulations, Geophys. J. Int., 145, 127-144, doi:10.1111/j.1365-246X.2001.00345.x, 2001.

Peltier, R. and LevyVehel, J.: Multifractional Brownian motion: Definition and preliminary results, J. Stochastic Process. Appl., Technical report INRIA 2645, 43 pp., 1995.

Peternell, M. and Kruhl, J. H.: Automation of pattern recognition and fractal-geometry-based pattern quantification, exemplified by mineral-phase distribution patterns in igneous rocks, Comput. Geosci., 35, 1415-1426, doi:10.1016/j.cageo.2008.11.001, 2009.

Pilkington, M. and Todoeschuck, J. P.: Fractal magnetization of continental crust, Geophys. Res. Lett., 20, 627-630, 1993.

Pilkington, M. and Todoeschuck, J. P.: Scaling nature of crustal susceptibilities, Geophys. Res. Lett., 22, 779-782, doi:10.1029/95GL00486, 1995.

Reed, J., Lipman, P., and Robertson, J.: Geologic map of the Latir Peak and Wheeler Peak Wildernesses and Columbine-Hondo Wilderness Study Area, Taos County, New Mexico, US Geological Survey Miscellaneous Field Studies Map MF-1570-B, pp. 1 Map, scale 1:50000, 1983.

Rehrig, W. A. and Reynolds, S. J.: Cordilleran Metamorphic Core Complexes, vol. Memoir 153, chap. Geologic and geochronologic reconnaissance of a northwest-trending zone of metamorphic core complexes in southern and western Arizona, Geol. Soc. Am., 131-157, 1980.

Reidi, R.: Multifractal processes, in: Theory and Applications of Long Range Dependence, edited by: Doukan, P., Oppenheim, G., and Taqqu, M., Birkhäuser, 625-715, 2003.

Saltus, R. and Haeussler, P.: Magnetic properties of Quaternary deposits, Kenai Peninsula, Alaska Implications for aeromagnetic anomalies of upper Cook Inlet, US Geological Survey Open-File Report 2004-1202, 1, 1-30, 2004.

Sanger, E. A. and Glen, J.: Density and Magnetic Susceptibility Values for Rocks in the Talkeetna Mountains and Adjacent Region, South-Central Alaska, US Geological Survey Open-File Report 03-268, 1, 1-44, 2003.

Schertzer, D. and Lovejoy, S.: The State of the Planet: Frontiers and Challenges in Geophysics Geophysical Monograph Series 150, vol. Geophysical Monograph Series 150, Uncertainty and Predictability in Geophysics: Chaos and Multifractal Insights, American Geophysical Union, 317-334, 2004.

Williams, P. L.: Geology, structure, and uranium deposits of the Moab quadrangle, Colorado and Utah, US Geological Survey I Map, I-360, 2 shts., scale 1:250 000, 1964.

Wrucke, C. and Armstrong, A.: Geologic map of the Whetstone Roadless Area and vicinity, Cochise and Pima Counties, Arizona, US Geological Survey Miscellaneous Field Studies Map MF-1614-B, pp. 1 Map, scale 1:48000, 1984. 